\title{
Control of Cationic Nanogel PEGylation in Heterogeneous ARGET ATRP Emulsion Polymerization with PEG Macromonomers
}

\author{
David S. Spencer ${ }^{1,2}$, Bryan C. Luu ${ }^{1}$, David W. Beckman ${ }^{1}$, and Nicholas A. Peppas ${ }^{1,2,3,4,5,6}$ \\ ${ }^{1}$ McKetta Department of Chemical Engineering, The University of Texas at Austin, Austin, Texas \\ 78712 \\ ${ }^{2}$ Institute of Biomaterials Drug Delivery and Regenerative Medicine, The University of Texas at \\ Austin, Austin, Texas 78712 \\ ${ }^{3}$ Department of Biomedical Engineering, The University of Texas at Austin, Austin, Texas 78712 \\ ${ }^{4}$ Division of Pharmaceutics, College of Pharmacy, The University of Texas at Austin, Austin, Texas \\ 78712 \\ ${ }^{5}$ Department of Pediatrics, The University of Texas at Austin, Austin, Texas 78712 \\ ${ }^{6}$ Department of Surgery and Perioperative Care, Dell Medical School, The University of Texas at \\ Austin, Austin, Texas 78712
}

\begin{abstract}
Crosslinked cationic nanoscale networks with hydrophobic cores are an environmentally robust alternative to self-assembled polymeric drug delivery carriers with respect to therapeutic encapsulation and stability to dilution. However, the ability to tune the degree of PEG incorporated into nanogels during synthesis is more challenging. In this work, biodegradable cationic nanogels were synthesized by ARGET ATRP emulsion polymerization in a single step. The density of PEG in the final nanogels ranged from zero to $40 \mathrm{wt} \%$ and was dependent on the feed concentration of PEG monomer, surfactant concentration, surfactant hydrophilic-lipophilic balance, and the ratio of cationic to nonionic surfactant. A comprehensive analysis of nanogel material properties as a function of PEG graft density is presented including analysis of composition, monomer conversion, thermal properties, size, surface charge, and degradation. This study provides a robust analysis for the synthesis of degradable cationic nanogels via a controlled radical polymerization with predictable degrees of PEGylation.
\end{abstract}

\section{Keywords}

ARGET ATRP; biodegradable; drug delivery; nanogel; poly(ethylene glycol) 


\section{INTRODUCTION}

Cationic nanomaterials are excellent candidates as carriers for drug and gene delivery because positively charged polymers readily interact with negatively charged cell membranes. ${ }^{1}$ Cationic carriers are of interest for delivery of siRNA, miRNA, sgRNA, and even proteins into cells thus forming the next generation of therapeutic delivery. ${ }^{2-4}$ Many natural and synthetic cationic materials have been explored for use as nanoscale carriers in drug and gene delivery including nanoparticles of cyclodextrin, $\operatorname{poly}(\beta$-amino esters), tertiary amine (meth)acrylates, chitosan, conjugated inorganic materials such as mesoporous silica and gold, and lipid nanoparticles. ${ }^{5-12}$

Ubiquitously, these carriers rely on polyethylene glycol (PEG) or similar hydrophilic materials to enhance circulation halflife, shield surface charge, and enhance stability in serum. Previous work in the drug delivery field has suggested that the use pendent PEG chains of at least $2 \mathrm{kDa}$ is required to achieve adequate stealth properties. ${ }^{13}$ However, optimal PEG surface density for nanoparticles spans a wide range and is a balance of attaining a sufficient stealth coating to enhance circulation half-life, yet not too dense to hinder drug release at the site of action. ${ }^{13}$ Reports in the literature suggest PEG densities in the range of 5-20 mol \% lead to the optimum PEG balance. ${ }^{13}$

The most common cationic formulations utilized for intracellular drug or protein delivery have been lipid nanoparticles and polymeric micelles. ${ }^{14}$ For lipid nanoparticles, PEG content can be modulated by the ratio of PEG-containing lipid incorporated during nanoparticle formation. Similarly, for polymeric micelles, PEG functionalized initiators are commonly utilized in controlled radical polymerizations to prepare diblock or triblock copolymers with a desired amount of PEG, prior to self-assembly.

Crosslinked nanopolymers are often preferred as they do not dissolve. ${ }^{15}$ Furthermore, crosslinked polymers containing ionizable groups can be utilized to synthesize nanopolymers with $\mathrm{pH}$ dependent swelling responses. ${ }^{16}$ However, the direct synthesis of nanoscale crosslinked polymers requires molecular separation of the crosslinking agent from other copolymerizing monomers so that a macroscale network is not formed. Nanoscale networks based upon 2-(diethylamino)ethyl methacrylate undergo a hydrophobic to hydrophilic transition near physiological pH ( 7.4). Due to the chemical crosslinks, this transition imparts $\mathrm{pH}$-dependent swelling properties. However, the increased hydrophobicity of the network at physiological $\mathrm{pH}$ values must be overcome to achieve colloidal stability in the collapsed state for therapeutic administration.

The synthesis of PEG-containing networks made from hydrophobic monomers typically requires postsynthesis crosslinking or postsynthesis PEGylation. ${ }^{17-24}$ Previously, we have demonstrated in our laboratory the use of an oil-in-water emulsion polymerization for the one-pot synthesis of cationic nanogels with hydrophobic cores and PEG tethers via both UVinitiated and ARGET ATRP schemes. ${ }^{25-30}$ Here, we report the ability to tune the degree of PEG decoration with respect to monomer feed and emulsion characteristics and a thorough characterization of the effect of the degree of PEGylation on the material properties of the biodegradable nanogels. 


\section{EXPERIMENTAL}

\section{Materials}

Poly(ethylene glycol) methyl ether methacrylate solution, henceforth designated as PEGMA2k, with Mn 2000, and in solutions $50 \mathrm{wt} \%$ in water, 2-(diethylamino)ethyl methacrylate (DEAEMA, 99\%), tert-butyl methacrylate (tBMA, 98\%), bis(2methacryloyl)oxyethyl disulfide (DSDMA), myristyl trimethylammonium bromide (MyTAB), ethyl a-bromoisobutyrate (EBiB, 98\%), L-ascorbic acid (AA), and triethylamine were purchased from Sigma-Aldrich. Tris(2-pyrdiylmethyl)amine was purchased from TCI America. Brij 30, Brij 35, copper (II)bromide (991\%), acetone-d6 (99.8\% D), and deuterium oxide $(99.8 \%$ D) were purchased from Acros Organics.

Tris(hydroxypropyl)phosphine (THP) and tris(2-carboxylethyl) phosphine (TCEP) were purchased from EMD Millipore. Tetrahydrofuran, acetone, hydrochloric acid, hexanes, and methylene chloride were purchased from Fisher Scientific. Poly(ethylene glycol) monomethyl ether monomethacrylate, $M_{\mathrm{n}} 1000$ (PEGMA1k) was purchased from Polysciences. All chemical were used as received. For reactions in $\mathrm{D}_{2} \mathrm{O}$, PEGMA2k was prepared as described in the literature. ${ }^{31}$

\section{Synthesis and Purification of Cationic Nanogels}

Nanogels were synthesized via activators regenerated by electron transfer (ARGET) ATRP polymerization in an oil/ water emulsion polymerization as previously described by Forbes et al. ${ }^{28}$ with modifications. Reactants were charged to $4 \mathrm{~mL}$ glass vials, sonicated into an emulsion using a 24-tip microtip sonicator probe, and initiated via the addition of excess ascorbic acid under nitrogen. Reactions were stopped via exposure to air and addition of $4 \mathrm{~N}$ $\mathrm{HCl}$ to a final concentration of $0.5 \mathrm{~N}$. Nanogels were purified via addition of acid and precipitation with a low dielectric solvent (acetone or THF) as described previously. ${ }^{25}$ Nanogels were collected via centrifugation at 4,000 rcf for $5 \mathrm{~min}$. After the last cycle, nanogels were suspended in ultrapure deionized water and dialyzed against ultrapure deionized water for 3 days and lyophilized.

\section{Characterization}

Nanogel Composition-Lyophilized crosslinked polymer nanoparticles were characterized with Attenuated Total Reflectance Fourier Transform Infrared (ATR-FTIR) Spectroscopy (Thermo Scientific Nicolet iS10) with a germanium crystal. Background spectra were collected immediately before each sample and used for background subtraction. In all cases, spectra were averaged over 64 scans.

Nanogel composition was estimated using ${ }^{1} \mathrm{H}$ nuclear magnetic resonance (NMR) Spectroscopy. Spectra were obtained using a $400 \mathrm{MHz}$ NMR (Varian Direct Drive 400 or Agilent MR 400) at $25^{\circ} \mathrm{C}$. To determine composition, dried nanogels were diluted in $\mathrm{D}_{2} \mathrm{O}$ at $10-15 \mathrm{mg} / \mathrm{mL}$ and degraded via addition of tris(2-carboxylethyl)phosphine to a final concentration of $10 \mathrm{mM}$ for $24 \mathrm{~h}$ prior to acquisition. Spectra were analyzed on MestReNova 10.0 software via integration of DEAEMA $(\delta 1.22,6 \mathrm{H})$, tBMA $(\delta 1.31,9 \mathrm{H})$, and PEGMA2k ( $83.55 \mathrm{ppm}, 176 \mathrm{H})$. 


\section{Thermal Analysis}

Thermal degradation of dried crosslinked nanogels ( $2-5 \mathrm{mg}$ ) was measured with thermal gravimetric analysis (TGA Q500, TA Instruments) from 30 to $550^{\circ} \mathrm{C}$ with a $10^{\circ} \mathrm{C} / \mathrm{min}$ heat rate under nitrogen.

Thermal transitions were measured using dynamic scanning calorimetry (TA Q2000, TA Instruments). A $5 \mathrm{mg}$ sample of dried crosslinked nanogels was tightly packed into an aluminum pan. Samples were heated to $130^{\circ} \mathrm{C}$ at $10^{\circ} \mathrm{C} / \mathrm{min}$ to erase thermal history and cooled to $275^{\circ} \mathrm{C}$ at $5{ }^{\circ} \mathrm{C} / \mathrm{min}$ prior to heating to $155^{\circ} \mathrm{C}$ at $10{ }^{\circ} \mathrm{C} / \mathrm{min}$.

Monomer Conversion-Conversion was determined via ${ }^{1} \mathrm{H}$ NMR via dilution of nanogel polymerizations in acetone-d6 at selected time points. Conversion of each monomer was followed via the disappearance of double bonds normalized to the initial time point utilizing TPMA as an internal standard. DEAEMA $(\delta 5.60,1 \mathrm{H}, \delta 6.03 \mathrm{ppm}, 1 \mathrm{H})$, tBMA $(\delta 5.50,1 \mathrm{H}$, $\delta 5.92,1 \mathrm{H})$ PEGMA2k $(\delta 5.62,1 \mathrm{H}, \delta 6.06,1 \mathrm{H})$, TPMA $(\delta 7.2-8.5,12 \mathrm{H})$.

Hydrodynamic Size and Electrophoretic Potential-Nanoparticle hydrodynamic diameters and electrophoretic potential were measured using a Malvern ZetaSizer NanoZS with a MPT-2 multi-purpose titrator. The hydrodynamic diameter was determined in $1 \times$ PBS from $\mathrm{pH} 4.0$ to 8.5. Each data point was the average of three runs with a minimum of 12 subruns. Electrophoretic potential was measured in $5 \mathrm{mM}$ phosphate buffer from $\mathrm{pH} 4.0$ to 10.0. Each data point is the average of three measurements.

Transmission Electron Microscopy-Transmission electron microscopy images were collected on a FEI Tecnai Transmission Electron Microscope at a magnification of 105,000 $\times$. Lyophilized nanogels were diluted in ultrapure deionized water at $0.25 \mathrm{mg} / \mathrm{mL}$, deposited on 400 mesh carbon-coated copper grids and stained with $2 \%$ uranyl acetate.

Nanoparticle Degradation-Nanoparticle degradation was investigated using dynamic light scattering count rates on a Malvern Zetasizer NanoZS. Nanogels were prepared degraded at $0.5 \mathrm{mg} / \mathrm{mL}$ in $1 \times$ PBS at pH 7.1 in $10 \mathrm{mM}$ THP. Single $10 \mathrm{~s}$ measurements were acquired sequentially at a set attenuation value and measurement height. Data were normalized to the initial time point.

\section{RESULTS AND DISCUSSION}

\section{Nanogel Composition}

PEGMA2k is a hydrophilic yet bulky monomer. Homopolymerization of this monomer at low degrees of polymerization result in star-like morphologies. ${ }^{31}$ At higher degrees of polymerization, brush type morphologies are observed. ${ }^{31}$ In previous work, we have utilized PEGMA2k macromonomer in heterogeneous emulsion polymerizations to stabilize polycationic nanogels. ${ }^{25,28}$ However, instability of nanoparticles polymerized via ARGET ATRP with this emulsion polymerization method prompted investigation into the extent of PEG incorporation and emulsion characteristics affecting PEG macromonomer conversion. 
Nanogel synthesis was conducted with increasing PEGMA2k feed concentration from 0 to $125 \mathrm{mM}$ (Table 1). The PEG monomer was varied independently of the monomers in the organic phase. Concentrations of PEGMA2k higher than $125 \mathrm{mM}$ were not investigated due to viscosity limitations. In this set of reactions, surfactant concentrations, organic phase volume, and organic phase composition were held constant.

Nanogels were synthesized, purified, and lyophilized prior to analysis of PEG content. Overall, increasing the nominal feed concentration of PEGMA2k led to a higher concentration of PEG in the final nanogel. Figure 1 clearly shows the increase in nanogel PEG content in the crosslinked state as determined by FTIR. Spectra were normalized to the characteristic methacrylate ester carbonyl stretching vibration at $1725 \mathrm{~cm}^{-1}$ Methacrylate polymers also have an ester C-O-C stretching vibration at $1142 \mathrm{~cm}^{-1}$. Here, the emergence of the ether asymmetric $\mathrm{C}-\mathrm{O}$ stretch peak was observed with increasing concentration of PEG in the feed at $1106 \mathrm{~cm}^{-1} .32$

Analysis of degraded nanogels via ${ }^{1} \mathrm{H}$ NMR spectroscopy was used to estimate nanogel composition. (Table 1 and Supporting Information, Fig. S1) PEGMA2k mol fractions from $0 \%$ to $5.8 \%$ ( $40 \mathrm{wt} \%$ ) were achieved in the final material by varying PEGMA2k feed concentration from 0 to $125 \mathrm{mM}$. The ratio of DEAEMA to tBMA remained constant across formulations.

In a similar manner, the feed concentration of PEGMA1k was varied from 0 to $200 \mathrm{mM}$. As expected, the PEGMA1k macromonomer behaved in a similar manner to PEGMA2k (Supporting Information, Table S1 and Supporting Information, Fig. S2). Higher mole fractions of PEGMA1k were incorporated onto nanogels compared to PEGMA2k with a range of PEG graft density from 0 to $16 \mathrm{~mol} \%(52 \mathrm{wt} \%)$. In both cases, the mole fraction of PEG in the final nanoparticle trended linearly with feed concentration (Supporting Information, Fig. S3).

\section{Thermal Analysis of Nanogels}

TGA studies were utilized to assess thermal degradation properties of the nanogels (Fig. 2). Mass loss under $100^{\circ} \mathrm{C}$ was attributed to bound water and accounted for 3-7 wt $\%$ of the nanogels. The fraction of mass loss between 180 and $285^{\circ} \mathrm{C}$ decreased as nanogel PEG content increased.

This trend was consistent with previous reports of ester group loss or anhydride formation with water liberation as a lower weight fraction of ester groups were present in the samples with higher PEG content. ${ }^{29,33}$ The fraction remaining was $2.8-4.3 \%$ and was highest for samples with no PEG. The broadening of the thermal degradation range with increasing PEG content was consistent with previous reports for PEG methacrylate chains. ${ }^{34}$

DSC was used to determine thermal transitions (Fig. 2). A distinct PEG melting endotherm was present and increased with increasing PEGMA2k feed concentration. In addition, the melting point shifted closer to the homopolymer value $\left(54^{\circ} \mathrm{C}\right)$ with increasing PEGMA2k feed concentration indicating an increase in the presence of PEG-rich domains. ${ }^{29,35}$ 


\section{Monomer Conversion in ARGET ATRP Emulsion Polymerization}

Cho et al. recently reported that ATRP polymerizations of PEG macromonomers in organic solvents were sensitive to temperature, pressure, and feed concentration. ${ }^{31}$ In their work, concentrations of $50 \mathrm{mM}$ PEGMA2k were required to observe any conversion. ${ }^{31}$ However, previous reports with PEGMA1k in ATRP inverse miniemulsion polymerization showed high conversion levels, indicating that high conversion can be achieved in aqueous reactions. 36

To understand the reactivity of the PEG macromonomers in this emulsion polymerization, monomer conversion was followed for nanogels with 0, 25, 50, and 100 mM PEGMA2k nominal feed concentration via ${ }^{1} \mathrm{H}$ NMR (Fig. 3 ). The protons of the vinyl peaks separated such that conversion of each monomer was followed independently with ${ }^{1} \mathrm{H}$ NMR (Supporting Information, Fig. S4). The organic phase monomers reacted to completion over the course of one hour independent of PEG feed concentration. After $4 \mathrm{~h}$, conversion of PEGMA2k was 73,81 , and $92 \mathrm{~mol} \%$ for 25,50 , and $100 \mathrm{mM}$ feed concentrations, respectively. However, after $24 \mathrm{~h}$, no detectable double bonds remained for any samples by ${ }^{1}$ H NMR spectroscopy.

The reaction of PEGMA2k to high conversion in conjunction with the composition of nanogels indicated that a large fraction of the PEGMA2k monomer reacted but was not incorporated into nanogels. Here, $\mathrm{Cu}^{\mathrm{II}} \mathrm{Br}_{2}$ and TPMA were used as the transition metal and ligand with $\mathrm{EBiB}$ as the initiator. These reagents are identical to those utilized for aqueous ARGET ATRP except for the substitution EBiB for the hydroxyl functionalized initiator 2hydroxyethyl 2-bromoisobutyrate. ${ }^{22}$ Thus, it is likely that initiation occurred in the water phase leading to PEGMA2k homopolymers that were removed during purification.

\section{Effect of Ligand, Copper, and Reducing Agent Concentration on Monomer Conversion}

A brief investigation of monomer conversion as a function of copper, ligand, and reducing agent ratios was used to determine the influence of ATRP reagents on the emulsion polymerization. A $75 \mathrm{mM}$ PEG2k feed concentration was utilized for all reactions with 150 ppm concentration of $\mathrm{Cu}^{\mathrm{II}} \mathrm{Br}_{2}$ (Table 2).

No difference in the conversion of any monomer was observed when the ratio of TPMA was reduced by a factor of eight (Fig. 4). However, when the reducing agent was increased eightfold, DEAEMA reached $86 \%$ conversion in 20 min compared to $43 \%$ in $20 \mathrm{~min}$ for the other two conditions. In addition, PEGMA2k conversion reached $66 \%$ in $1 \mathrm{~h}$ with the eightfold increase in reducing agent and did not react further. The polymerizations with lower concentration of reducing agent reached full conversion after $24 \mathrm{~h}$.

The increase in the rate of polymerization was consistent with a similar report for PEG graft monomers in miniemulsion with increasing concentrations of hydrazine. ${ }^{37}$ Furthermore, the lower degree of conversion with an increase in reducing agent is consistent with previous reports of higher termination rate constants in water when using ascorbic acid. ${ }^{38}$ 


\section{Effect of Surfactant on Nanogel Composition}

PEGMA2k is a very hydrophilic monomer. To participate in the reaction, the monomer must be able to interact at the emulsion boundary layer. As such, the concentration of surfactant relative to the concentration of PEGMA2k as well as the hydrophilic-lipophilic character of the surfactants used will be critical parameters in the final degree of PEGylation. It is important to note that the PEG monomer can also act as a stabilizer. ${ }^{39}$

Surfactant concentration, the ratio of cationic surfactant to nonionic surfactant, and the ratio of two nonionic surfactant were varied in a set of 18 polymerizations. Surfactant concentration was adjusted between 5 and $40 \mathrm{mg} / \mathrm{mL}(0.5-4 \%)$ (Table 3).

Two primary end-point parameters were compared for each nanogel formulation, namely PEG molar density and collapsed hydrodynamic size. As shown in Figure 5, the degree of PEGylation increased with increasing surfactant concentration from 10 to $40 \mathrm{mg} / \mathrm{mL}$. However, the lowest surfactant concentration did not follow this trend and had a higher degree of PEG of the surface.

At a surfactant concentration of $20 \mathrm{mg} / \mathrm{mL}$, the influence of the ratio of cationic surfactant to nonionic surfactant as well as the ratio of two nonionic surfactants were analyzed.

Specifically, 4 weight percentages of cationic surfactant $(6.75,13.5,27$, and $54 \mathrm{wt} \%)$ were studied with 3 combinations of nonionic surfactants (100\% Brij 30, 100\% Brij 35, or 50/50 Brij 30/Brij 35). The data are displayed on a scale of calculated hydrophilic-lipophilic balance (HLB) values using the following values (Brij 305 9.7, Brij 355 16.9, Mytab 5 22.35). ${ }^{40-43}$

The best-fit regression for both collapsed hydrodynamic size and PEG incorporation was second order with respect to HLB and first order with respect to cationic surfactant fraction (Supporting Information, Table S2).

Decreasing the cationic surfactant ratio led to higher degree of PEG incorporation into nanogels, but also resulted in larger nanogels in the collapsed state. PEG incorporation into nanogels reached a minimum at an HLB of $\sim 17.5$, while collapsed hydrodynamic size reached a minimum at an HLB of $\sim 14.5$.

This experiment identified the tradeoff between HLB, surfactant concentration, and surfactant ratios. This approach can be utilized to target a desired degree of PEGylation, while minimizing surfactant concentration and targeting the desired size range for the application of interest.

\section{Nanogel pH-Dependent Swelling and Zeta Potential}

PEG is widely known to enhance particle colloidal stability and enhance circulation halflife. To investigate the responsive nature of nanogels with increasing PEG graft density, hydrodynamic size and electrophoretic potential were analyzed as a function of $\mathrm{pH}$ (Fig. 6). Nanogels were $\sim 75 \mathrm{~nm}$ in the collapsed state and $120 \mathrm{~nm}$ in the swollen state.

Nanogels polymerized in the absence of PEG were unstable and aggregated above $\mathrm{pH} 6.5$ (off scale). Nanoparticle with feed ratios of $25 \mathrm{mM}$ resulted in slight aggregation at $\mathrm{pH}>6.5$ 
as observed by tailing in the size profile and higher polydispersity. However, formulations with above $50 \mathrm{mM}$ PEGMA2k in the feed were stable over the range of $\mathrm{pH}$ tested with a characteristic sigmoidal swelling response and did not display a hysteresis effect upon titration from $\mathrm{pH} 4$ to $\mathrm{pH} 8.5$ and then $\mathrm{pH} 8.5$ to $\mathrm{pH} 4$ (Supporting Information, Fig. S5).

As described in the literature, increased concentrations of PEG will lead to increased charge shielding. At pH 7.4 the apparent zeta potential was $\sim 20 \mathrm{mV}$ compared to $5 \mathrm{mV}$ for $100 \mathrm{mM}$ formulations. Charge shielding has a major influence on cellular interactions, and thus the ability to tune this parameter is crucial. Furthermore, in modulating properties for this scheme, it is important to note that colloidal stability at neutral $\mathrm{pH}$ is primarily driven by PEG content and monomer hydrophobicity.

Representative TEM images (Fig. 7) demonstrate the spherical morphology of nanogels with diameters similar to the hydrodynamic diameter of the collapsed state.

\section{Biodegradability of Nanogels}

Another crucial parameter for the utility of crosslinked nanoparticle in drug delivery applications is the ability to degrade in response to environmental cues. Disulfide bonds are a popular choice for degradable nanoparticle systems due to the presence of intracellular glutathione. ${ }^{44}$ Here degradable crosslinks were incorporated during polymerization with DSDMA. The degradable characteristics are linked to the degree of PEGylation. Here, that tradeoff is present in the rate of degradation at $\mathrm{pH} 7.1$ in $1 \times$ PBS. As shown in Figure 8, as the degree of PEGylation increased the time required to degrade nanogels increased from 2 to 4 days. This trends with the degree of PEG charge shielding observed from zeta potential measurements. Finally, GPC refractive index traces indicate that polymers increase in molecular weight with increasing PEGMA2k in the feed (Supporting Information, Fig. S6).

\section{CONCLUSIONS}

Reaction conditions were developed for the tunable one-step incorporation of PEG grafts onto biodegradable $\mathrm{pH}$ responsive polymer nanoparticles in dispersed media. PEG incorporation into nanogels increased with increasing PEGMA2k feed and resulted in nanogels that contained up to $40 \mathrm{wt} \%$ PEG grafts. The modulation of surfactant chemistry utilized for polymerization further increased the ability to tune the degree of PEG grafts onto the surface of nanogels at a set PEGMA2k feed concertation. The $\mathrm{pH}$-responsive properties of the nanogels demonstrated the tradeoff between the concentration of PEGMA2k needed to impart colloidal stability and the degree of charge shielding. The incorporation of a disulfide crosslinking agent rendered these polymers biodegradable, with biodegradation dependent on the degree of charge shielding. The work detailed here describes a method to tune the amount of PEG on the surface in a single step without the need for additional conjugation reactions or crosslinking steps. This approach will enable the efficient synthesis of cationic nanomaterials with desired material properties for intracellular drug delivery applications. 


\section{Supplementary Material}

Refer to Web version on PubMed Central for supplementary material.

\section{ACKNOWLEDGMENTS}

The authors would like to acknowledge the Microscopy and Imaging Facility of the Institute for Cellular and Molecular Biology at The University of Texas at Austin for the use of TEM and Marissa Wechsler for acquisition of TEM images. This work was supported in part by the Cockrell Family Regents Chair. D.S.S. acknowledges support from the National Science Foundation Graduate Research Fellowship Program (DGE-1610403).

\section{REFERENCES AND NOTES}

1. Whitehead KA, Langer R, Anderson DG, Nat. Rev. Drug Disc 2009, 8, 129.

2. Zuris JA, Thompson DB, Shu Y, Guilinger JP, Bessen JL, Hu JH, Maeder ML, Joung JK, Chen Z-Y, Liu DR, Nat. Biotechnol 2015, 33, 73. [PubMed: 25357182]

3. Cho K, Wang X, Nie S, Chen Z, Shin DM, Clin. Cancer Res 2008, 14, 1310. [PubMed: 18316549]

4. Chen Y,Gao D-Y,Huang L,Adv.Drug Deliv.Rev2015,81,128. [PubMed: 24859533]

5. Kanasty R, Dorkin JR, Vegas A, Anderson D, Nat. Mater 2013, 12, 967. [PubMed: 24150415]

6. Kim HJ, Kim A, Miyata K, Kataoka K, Adv. Drug Deliv. Rev 2016, 104, 61.

7. Jin L,Zeng X,Liu M,Deng Y,He N, Theranostics 2014, 4, 240. [PubMed: 24505233]

8. Blanco E, Shen H, Ferrari M, Nat. Biotechnol 2015, 33, 941. [PubMed: 26348965]

9. Gaucher G, Dufresne M-H, Sant VP, Kang N, Maysinger D, Leroux J-C, J. Control. Release 2005, 109, 169. [PubMed: 16289422]

10. Liechty WB, Kryscio DR, Slaughter BV, Peppas NA, Annu. Rev. Chem. Biomol. Eng 2010, 1, 149. [PubMed: 22432577]

11. Davis ME, Mol. Pharm 2009, 6, 659. [PubMed: 19267452]

12. Spencer DS, Puranik AS, Peppas NA, Curr. Opin. Chem. Eng 2015, 7, 84. [PubMed: 25621200]

13. Suk JS, Xu Q, Kim N, Hanes J, Ensign LM, Adv. Drug Deliv. Rev 2016, 99, 28. [PubMed: 26456916]

14. Cooper BM, Putnam D, ACS Biomater. Sci. Eng 2016, 2, 1837.

15. Chacko RT, Ventura J, Zhuang JM, Thayumanavan S, Adv. Drug Deliv. Rev 2012, 64, 836. [PubMed: 22342438]

16. Gao W, Chan J, Farokhzad OC, Mol. Pharm 2010, 7, 1913. [PubMed: 20836539]

17. Rösler A, Vandermeulen GWM, Klok H-A, Adv. Drug Deliv. Rev 2012, 64, 270.

18. Li YT, Lokitz BS, Armes SP, McCormick CL, Macromolecules 2006, 39, 2726.

19. Oh JK, Drumright R, Siegwart DJ, Matyjaszewski K, Progr. Polym. Sci 2008, 33, 448.

20. Ryu JH, Chacko RT, Jiwpanich S, Bickerton S, Babu RP, Thayumanavan S, J. Am. Chem. Soc 2010, 132, 17227. [PubMed: 21077674]

21. Min K, Matyjaszewski K, Central Eur. J. Chem 2009, 7, 657.

22. Simakova A, Averick SE, Konkolewicz D, Matyjaszewski K, Macromolecules 2012, 45, 6371.

23. Qiu J, Charleux B, Matyjaszewski K, Progr. Polym. Sci2001, 26, 2083.

24. Wagner AM, Spencer DS, Peppas NA, J. Appl. Polym. Sci. DOI: 10.1002/app.46154.

25. Fisher OZ, Peppas NA, Macromolecules 2009, 42, 3391. [PubMed: 20526378]

26. Fisher O, Kim T, Dietz S, Peppas N, Pharma. Res 2009, 26, 51.

27. Liechty WB, Scheuerle RL, Peppas NA, Polymer 2013, 54, 3784.

28. Forbes DC, Creixell M, Frizzell H, Peppas NA, Eur. J. Pharma. Biopharma 2013, 84, 472.

29. Forbes DC, Peppas NA, Polymer 2013, 54, 4486.

30. Forbes DC, Peppas NA, ACS Nano. 2014, 8, 2908. [PubMed: 24548237]

31. Cho HY, Krys P, Szczesniak K, Schroeder H, Park S, Jurga S, Buback M, Matyjaszewski K, Macromolecules 2015, 48, 6385. 
32. Infrared Characteristic Group Frequencies Tables and Charts, 2nd ed.; John Wiley \& Sons: Chichester, England, 1994.

33. Cervantes-Uc JM, Cauich-Rodríguez JV, HerreraKao WA, Vázquez-Torres H, Marcos-Fernández A, Polym. Degrad. Stab 2008, 93, 1891.

34. Soeriyadi AH, Li G-Z, Slavin S, Jones MW, Amos CM, Becer CR, Whittaker MR, Haddleton DM, Boyer C, Davis TP, Polym. Chem 2011, 2, 815.

35. Murthy NS, Wang W, Kohn J, Polymer 2010, 51, 3978. [PubMed: 20802835]

36. Oh JK, Tang C, Gao H, Tsarevsky NV, Matyjaszewski K, J. Am. Chem. Soc 2006, 128, 5578. [PubMed: 16620132]

37. Dong H, Matyjaszewski K, Macromolecules 2010, 43, 4623.

38. Min K, Gao H, Matyjaszewski K, Macromolecules 2007, 40, 1789.

39. Amalvy JI, Wanless EJ, Li Y, Michailidou V, Armes SP, Duccini Y, Langmuir 2004, 20, 8992. [PubMed: 15461478]

40. Griffin WC, J. Cosmet. Sci 1949, 1, 311.

41. Davies J, Proc. 2nd Intern. Congr. Surface Activity, Butterworths Scientific Publication: London, 1957, p 426.

42. Ho OB, J. Colloid Interface Sci 1998, 198, 249.

43. Proverbio ZE, Bardavid SM, Arancibia EL, Schulz PC, Colloids Surf. A Physicochem. Eng. Asp 2003, 214, 167.

44. Lushchak VI, J. Amino Acids 2012, 2012, 736837. [PubMed: 22500213] 


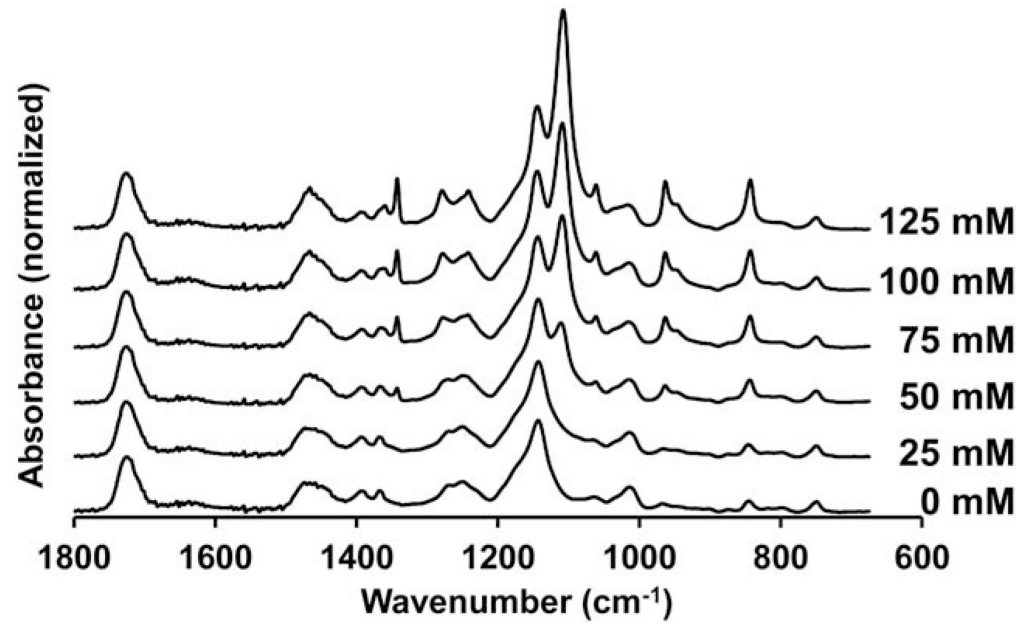

FIGURE 1.

ATR-FTIR spectra of cationic nanogels with varied PEGMA2k feed concentrations from 0 to $125 \mathrm{mM}$. All spectra are normalized to the ester carbonyl peak at $1725 \mathrm{~cm}^{-1}$. Spectra shifted vertically for clarity. 

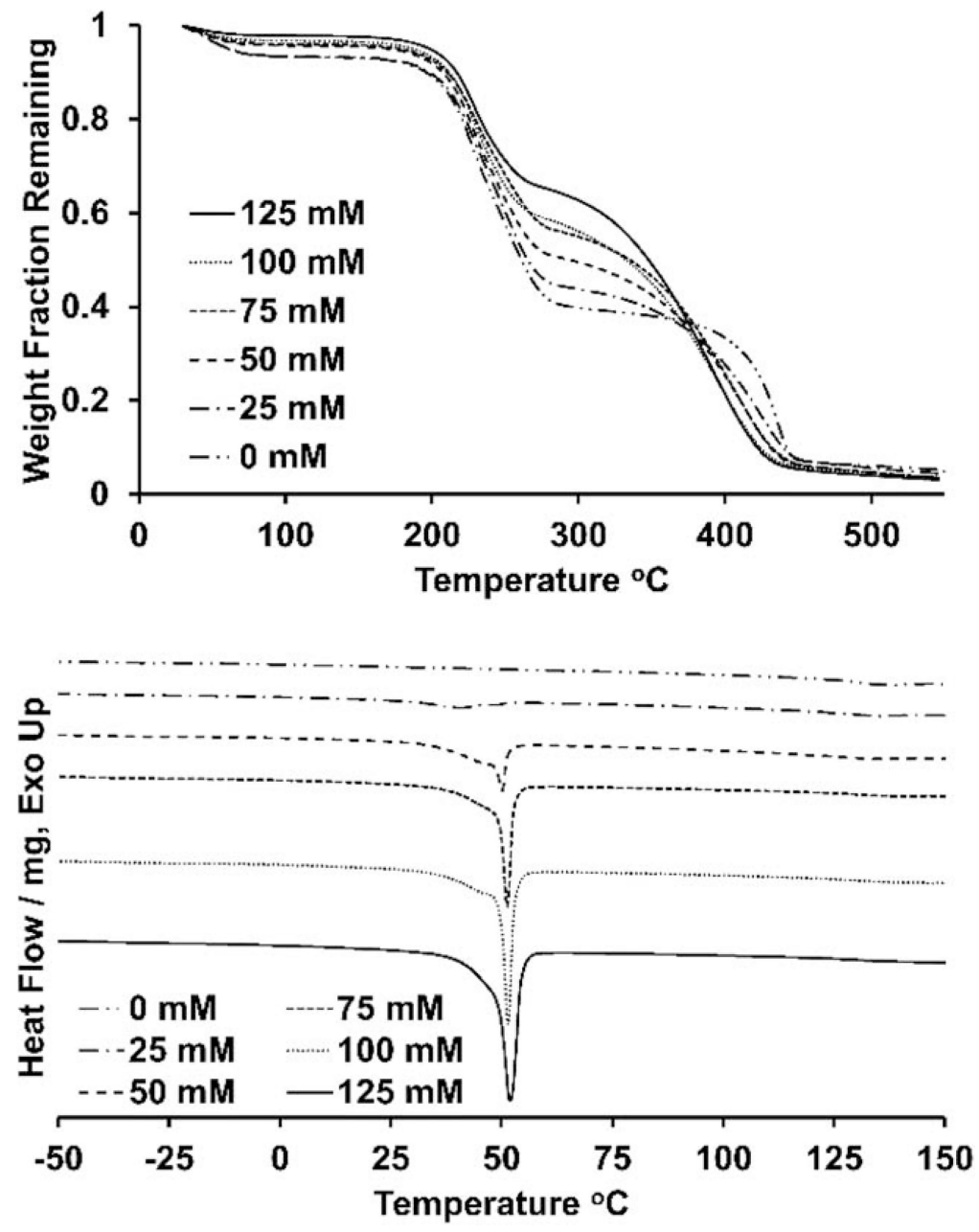

FIGURE 2.

Thermogravimetric analysis (top) and dynamic scanning calorimetry (bottom) of nanogels synthesized with increasing PEGMA2k molar feed ratios. DSC curves are shifted vertically for clarity. 

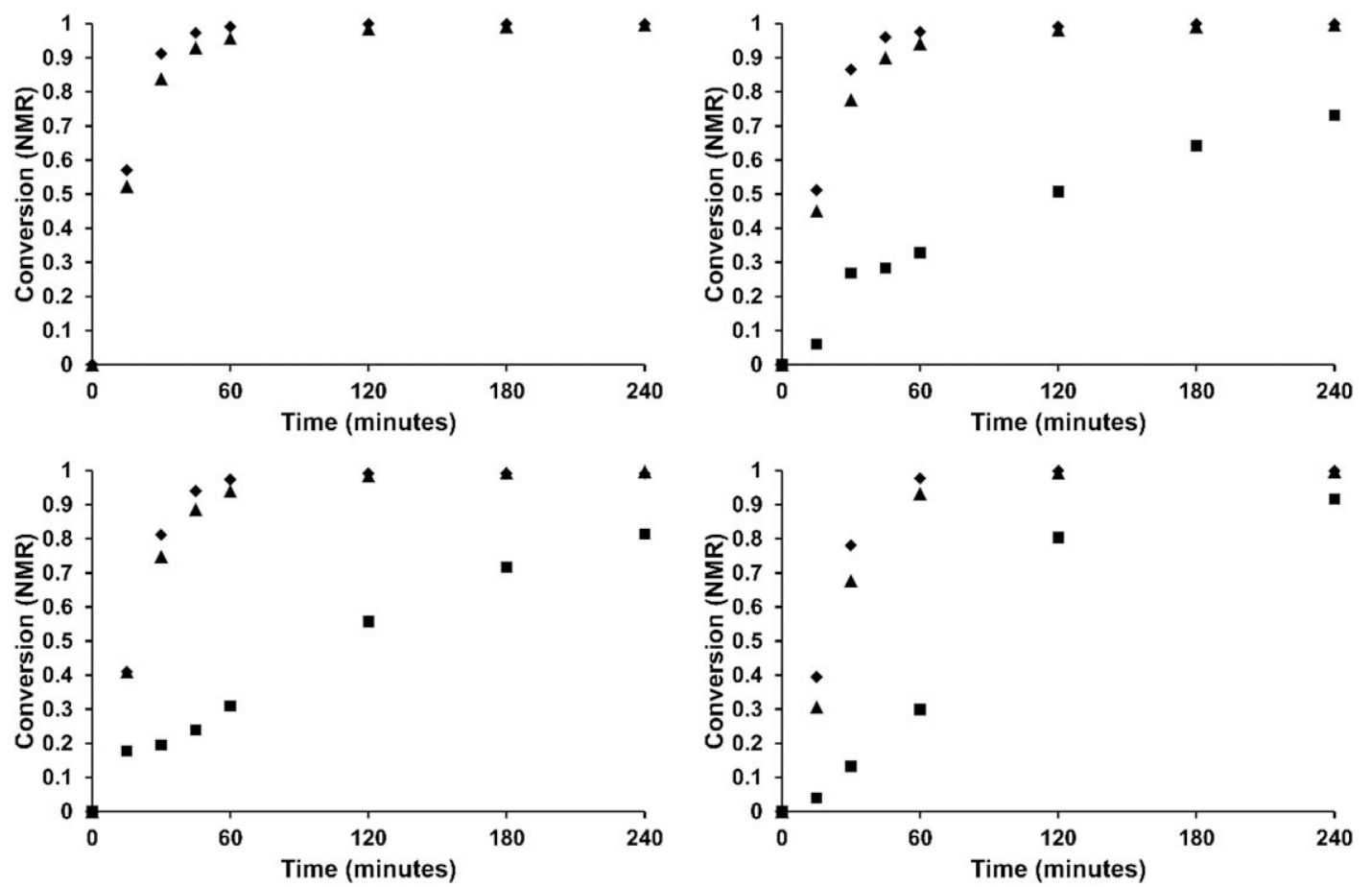

FIGURE 3.

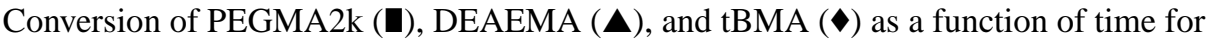
nanogels polymerized $0,25,50$, and $100 \mathrm{mM}$ PEGMA2k in the feed measured via H NMR. Conversion was determined via ${ }^{1} \mathrm{H}$ NMR via dilution of the reaction in acetone-d6. 

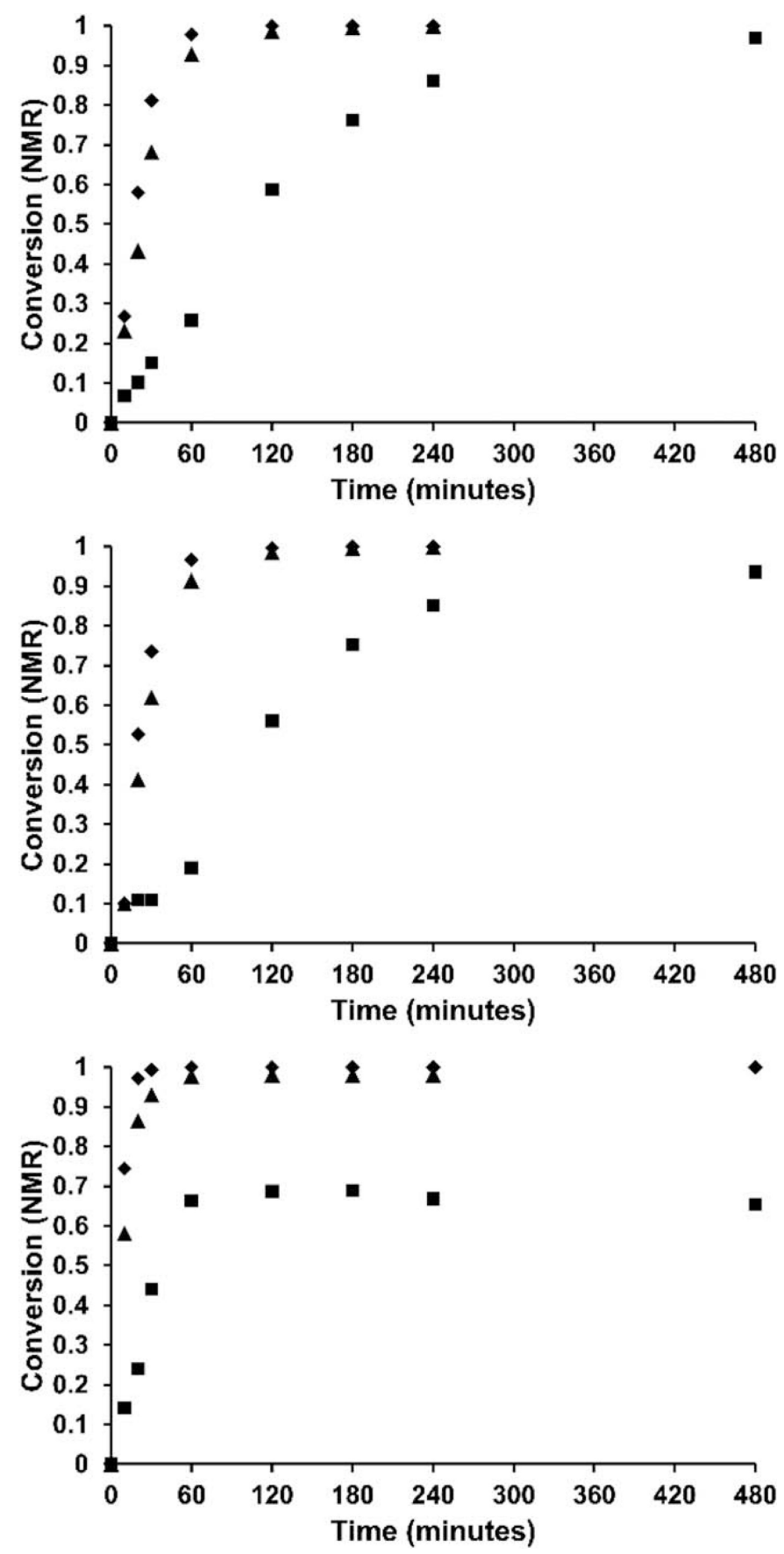

FIGURE 4.

Conversion of PEGMA2k ( $\mathbf{\square})$, DEAEMA $(\boldsymbol{\Delta})$, and tBMA $(\bullet)$ as a function of time for nanogels polymerized $75 \mathrm{mM}$ PEGMA2k in the feed with $\mathrm{Cu}(\mathrm{II})$ : TPMA: ascorbic acid ratios of 1:8:2 (top), 1:1:2 (middle), and 1:8:16 (bottom) and polymerized under conditions from Table 2. Conversion was determined via ${ }^{1} \mathrm{H}$ NMR from dilution of the reaction in acetone-d6. 

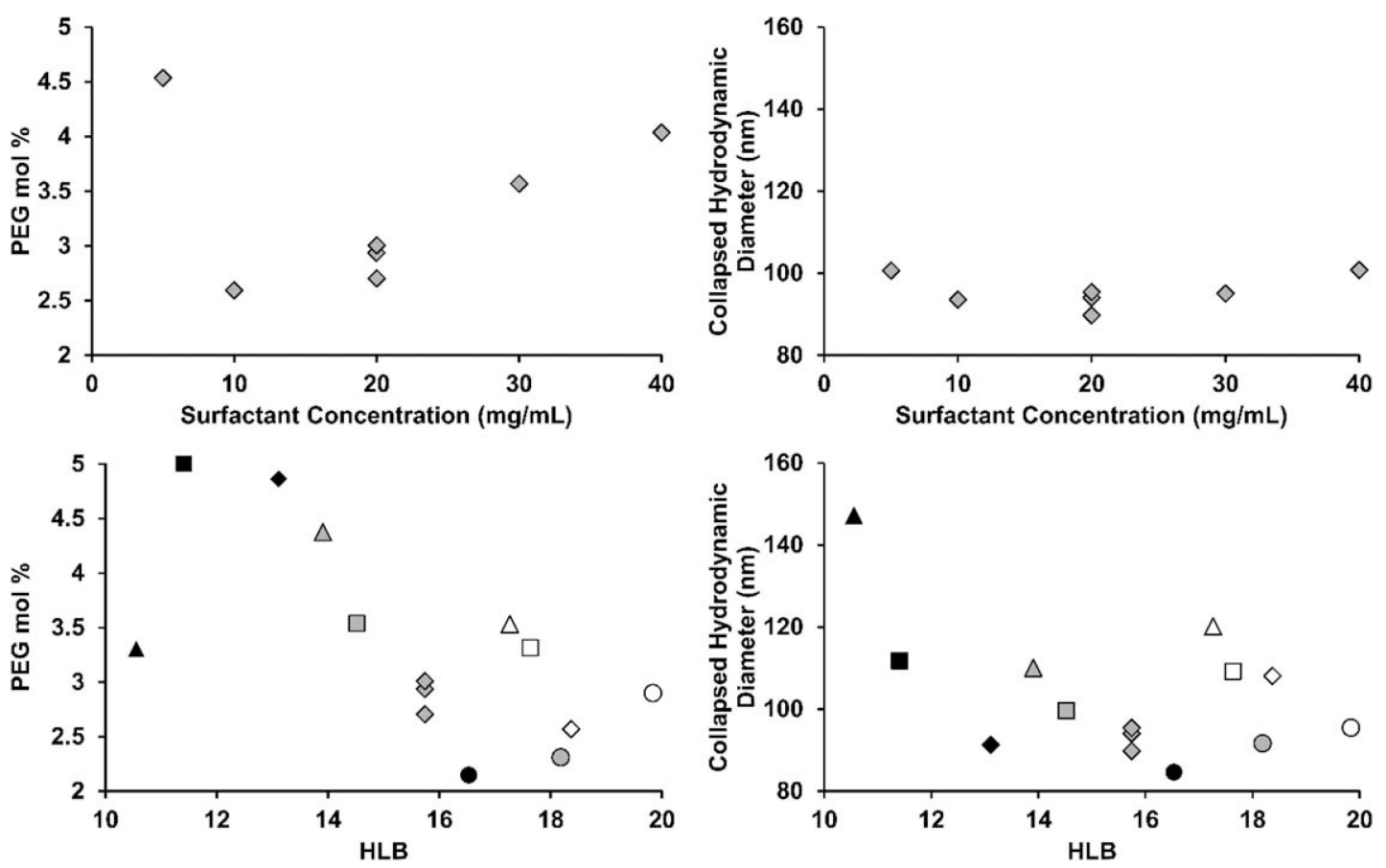

FIGURE 5.

Degree of nanogel PEGylation as a function of surfactant concentration and calculated value of HLB. The fraction of cationic surfactant is denoted by shape (triangle, square, diamond, and circle for $6.75 \%, 13.5 \%, 27 \%$, and $54 \mathrm{wt} \%$ MyTAB, respectively). Black (100\% Brij 30), white(100\% Brij35), orgray(50/50Brij30/Brij35)shapes denote the ratio of non ionic surfactant that accounts for the balance of surfactant.PEG molfraction was calculated from ${ }^{1} \mathrm{H}$ NMR and collapsed hydrodynamic size was measure dviadynamiclight scattering at pH8.0in $1 \times$ PBS. 

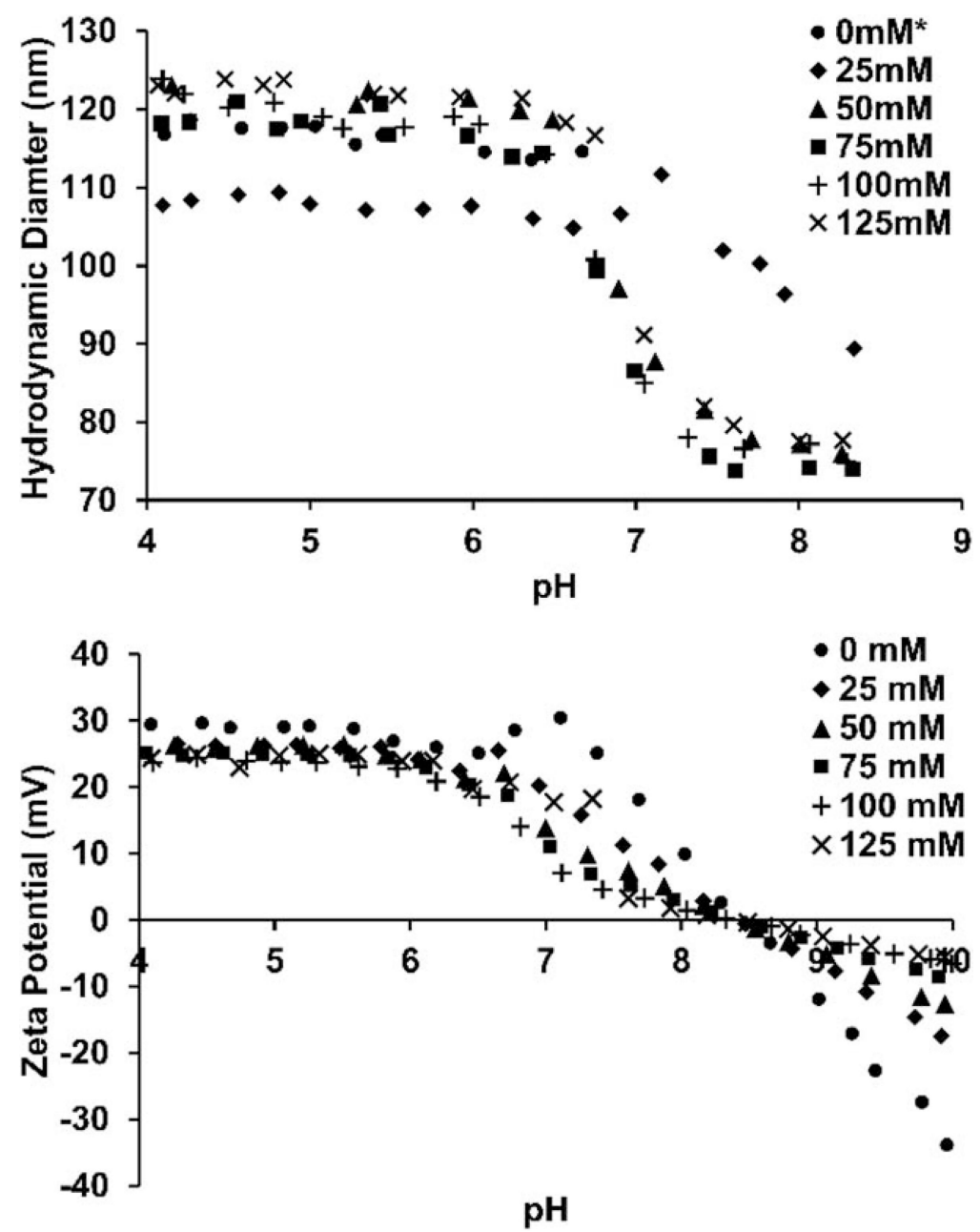

FIGURE 6.

Dynamic light scattering and electrophoretic potential of nanogels with PEGMA2k feed concentration 0-125 mM. Hydrodynamic size was measured with nanogels in $13 \mathrm{PBS}$ at 0.5 $\mathrm{mg} / \mathrm{mL}$ from $\mathrm{pH} 4$ to $\mathrm{pH}$ 8.5. Nanogels synthesized with $0 \mathrm{mM}$ PEGMA2k aggregated significantly and are off scale. All data points are the average of three measurements with a minimum of 12 subruns for each measurement. Electrophoretic potential was measured for nanogels at a concentration of $0.5 \mathrm{mg} / \mathrm{mL}$ in $5 \mathrm{mM}$ phosphate buffer from $\mathrm{pH} 4$ to 10 . All data points are the average of 3 measurements. 


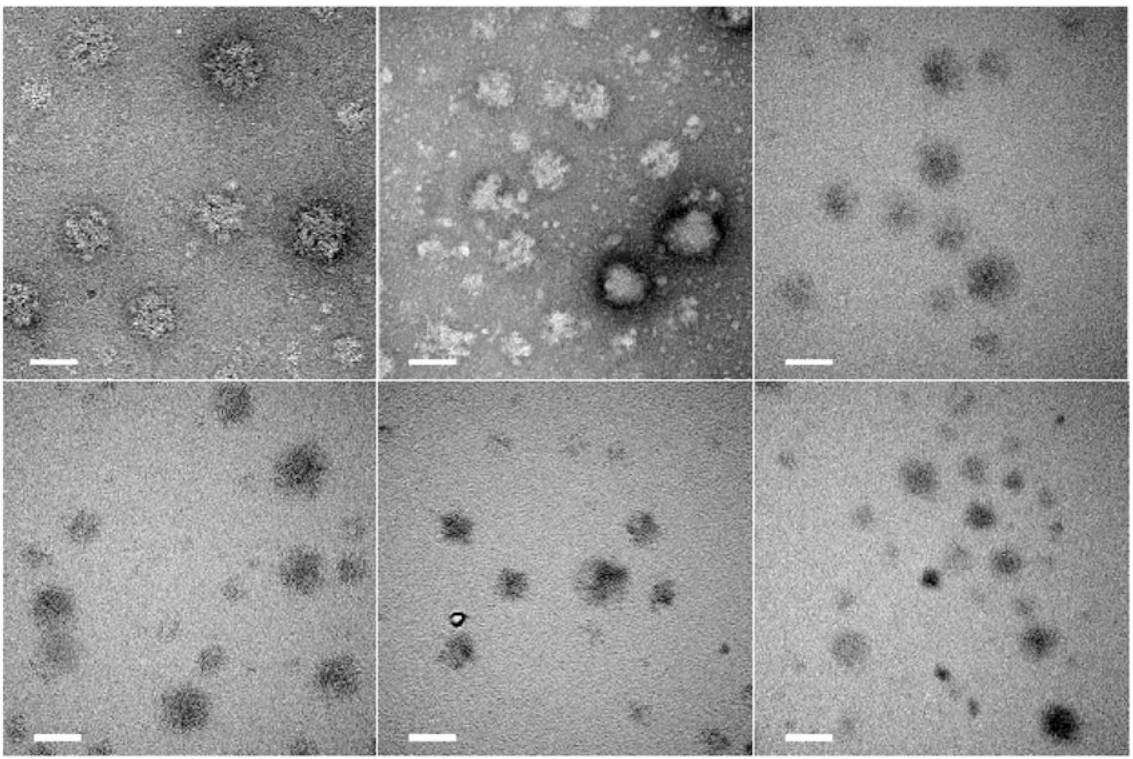

FIGURE 7.

Transmission electron microscopy images nanogels with increasing PEG content (top left to right 0,25 , and $50 \mathrm{mM}$; bottom left to right 75,100 , and $125 \mathrm{mM}$ ) Nanogels were suspended at $0.25 \mathrm{mg} / \mathrm{mL}$ in ultrapure DI water and deposited on 400 mesh carbon-coated copper grids and stained with $2 \%$ uranyl acetate. Images were taken at $105,000 \times$ magnification. Scale bar represents $100 \mathrm{~nm}$. 


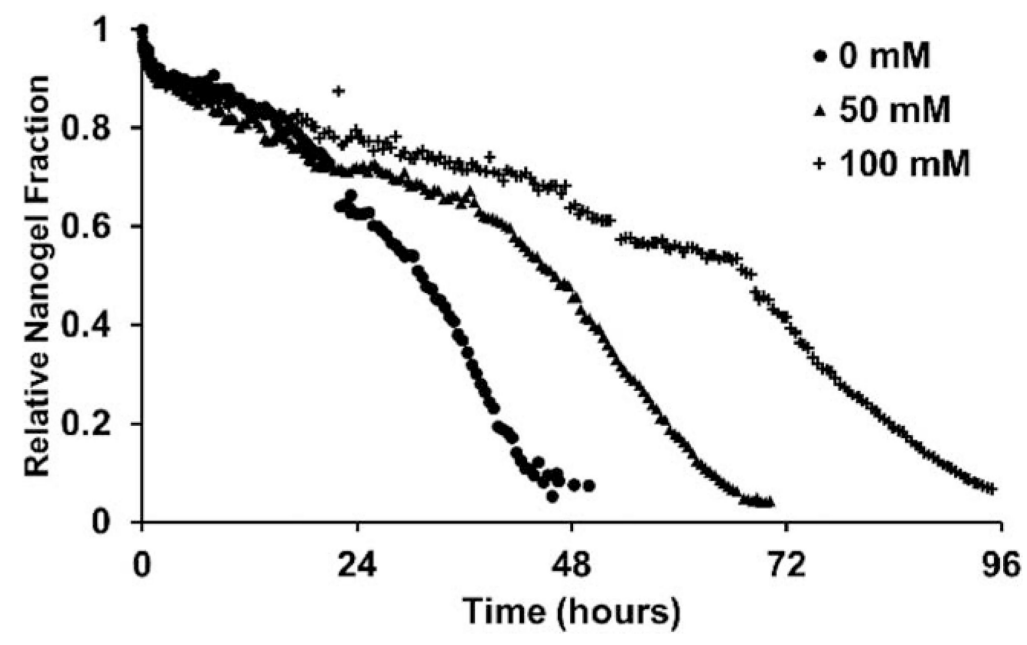

FIGURE 8.

Nanogel degradation in the presence of reducing agent. Dynamic light scattering count rate was measured sequentially for nanogels with 0,50 , or 100 mM PEGMA2k feed concentrations at $0.5 \mathrm{mg} / \mathrm{mL}$ in $1 \times \mathrm{PBS}$ pH 7.1 with $10 \mathrm{mM}$ THP. Data points represent single $10 \mathrm{~s}$ runs normalized to the initial time point. 


\section{Table 1}

Molar Feed Ratio and Composition of Cationic Nanogels Synthesized with Increasing Feed Concentrations of PEGMA2k

\begin{tabular}{|c|c|c|c|c|c|c|}
\hline \multirow[b]{2}{*}{ PEGMA2k]o $(\mathrm{mM})^{a}$} & \multicolumn{3}{|c|}{ Nominal Molar Feed Ratio } & \multicolumn{3}{|c|}{ Nanogel Molar Composition ( ${ }^{1} \mathrm{H}$ NMR } \\
\hline & DEAEMA & tBMA & PEGMA2k & DEAEMA & tBMA & PEGMA2k \\
\hline 0 & 75.0 & 25.0 & 0.0 & 75.3 & 24.7 & 0.0 \\
\hline 25 & 70.5 & 23.5 & 6.0 & 72.9 & 26.4 & 0.7 \\
\hline 50 & 66.5 & 22.2 & 11.3 & 73.1 & 25.1 & 1.7 \\
\hline 75 & 63.0 & 21.0 & 16.1 & 71.4 & 25.0 & 3.6 \\
\hline 100 & 59.8 & 19.9 & 20.3 & 72.4 & 23.6 & 3.9 \\
\hline 125 & 56.9 & 19.0 & 24.2 & 70.9 & 23.2 & 5.8 \\
\hline
\end{tabular}

${ }^{a}$ All reactions were carried out at $25^{\circ} \mathrm{C}$ for $16 \mathrm{~h}$. For all reactions, the organic phase was maintained at $7.5 \mathrm{vol} \%$ and had a constant composition $[\mathrm{I}]_{0} /[\mathrm{DEAEMA}]_{0} /[\mathrm{tBMA}]_{0} /[\mathrm{DSDMA}]_{0} 54 / 75 / 25 / 1.25$. The concentration of catalyst was maintained at $\left[\mathrm{Cu} \mathrm{II}_{\mathrm{Br}}\right]_{0}=150$ ppm based on total volume with the following ratios [TPMA $]_{0} /\left[\mathrm{Cu}^{\mathrm{II}} \mathrm{Br}_{2}\right]_{0} /[\mathrm{AA}]_{0} 58 / 1 / 2$. Surfactant concentration was held constant at $20 \mathrm{mg} / \mathrm{mL}$ with $5.4 \mathrm{mg} / \mathrm{mL}$ MyTAB, $7.3 \mathrm{mg} / \mathrm{mL}$ Brij 30, and $7.3 \mathrm{mg} / \mathrm{mL}$ Brij 35 . 


\section{Table 2}

Molar Ratios of ARGET ATRP Reagents Used for Synthesis of Cationic Nanogels

\begin{tabular}{llll}
\hline & \multicolumn{4}{l}{ Molar Ratios for ARGET ATRP } \\
\cline { 2 - 4 } Entry $^{\boldsymbol{a}}$ & $\mathbf{C u ( I I )}$ & TPMA & AA \\
1 & 1 & 8 & 2 \\
2 & 1 & 1 & 2 \\
3 & 1 & 8 & 16 \\
\hline
\end{tabular}

${ }^{a}$ All reactions were carried out at $25^{\circ} \mathrm{C}$ for $24 \mathrm{~h}$ in deuterium oxide with an initial concentration of $75 \mathrm{mM}$ PEGMA2k. The concentration of copper was maintained at $\left[\mathrm{Cu}^{\mathrm{II}} \mathrm{Br} 2\right] 05150 \mathrm{ppm}$ based on total volume. The organic phase was maintained at $7.5 \mathrm{vol} \%$ and had a constant composition $[\mathrm{I}]_{0} /[\mathrm{DEAEMA}]_{0} /[\mathrm{tBMA}]_{0} /[\mathrm{DSDMA}]_{0} 54 / 75 / 25 / 1.25$. Surfactant concentration was held constant at $20 \mathrm{mg} / \mathrm{mL}$ with $5.4 \mathrm{mg} / \mathrm{mL}$ MyTAB, $7.3 \mathrm{mg} / \mathrm{mL}$ Brij 30, and $7.3 \mathrm{mg} / \mathrm{mL}$ Brij 35 . 
Table 3

Surfactant Concentrations Used for the Polymerization of Nanogels

\begin{tabular}{|c|c|c|c|c|}
\hline Entry $^{a}$ & MyTAB & Brij 30 & Brij 35 & Total \\
\hline 1 & 1.35 & 1.83 & 1.83 & 5 \\
\hline 2 & 2.7 & 3.65 & 3.65 & 10 \\
\hline 3 & 5.4 & 7.3 & 7.3 & 20 \\
\hline 4 & 5.4 & 7.3 & 7.3 & 20 \\
\hline 5 & 5.4 & 7.3 & 7.3 & 20 \\
\hline 6 & 8.1 & 10.95 & 10.95 & 30 \\
\hline 7 & 10.8 & 14.6 & 14.6 & 40 \\
\hline 8 & 1.35 & 18.65 & 0 & 20 \\
\hline 9 & 1.35 & 9.33 & 9.33 & 20 \\
\hline 10 & 1.35 & 0 & 18.65 & 20 \\
\hline 11 & 2.7 & 17.3 & 0 & 20 \\
\hline 12 & 2.7 & 8.65 & 8.65 & 20 \\
\hline 13 & 2.7 & 0 & 17.3 & 20 \\
\hline 14 & 5.4 & 14.6 & 0 & 20 \\
\hline 15 & 5.4 & 0 & 14.6 & 20 \\
\hline 16 & 10.80 & 9.20 & 0 & 20 \\
\hline 17 & 10.80 & 4.60 & 4.60 & 20 \\
\hline 18 & 10.80 & 0 & 9.20 & 20 \\
\hline
\end{tabular}

${ }^{a}$ All reactions were carried out at $25^{\circ} \mathrm{C}$ for $16 \mathrm{~h}$. For all reactions, the oil phase was maintained at $7.5 \mathrm{vol} \%$ and had a constant composition $\left.[\mathrm{I}]\right]_{0} /$ $[\text { DEAEMA }]_{0} /[\text { tBMA }]_{0} /[\text { DSDMA }]_{0}=4 / 75 / 25 / 1.25$ with $[\text { PEGMA2k }]_{0}=100 \mathrm{mM}$. The concentration of transition metal was maintained at $\left[\mathrm{Cu}^{\mathrm{II}} \mathrm{Br}_{2}\right] 0=150 \mathrm{ppm}$ based on total volume with the following ratios $[\mathrm{TPMA}] 0 /\left[\mathrm{Cu}{ }^{\mathrm{II}} \mathrm{Br} 2\right] 0 /[\mathrm{AA}] 0=8 / 1 / 2$. 